\title{
Influence of different chromium applications on vegetative growth and chemical constituents of Tilia cordata seedlings
}

\author{
Rawia A. Eid, Hashish, Kh. I., Azza A.M. Mazhar and Nahed G. Abd El Aziz
}

Ornamental Plants and Woody Trees Dept. National Research Centre, 33Bohouth St. Dokki, Giza, Egypt

\author{
Received: 15 Oct. 2020 / Accepted 10 Dec. 2020 / Publication date: 20 Dec. 2020
}

\begin{abstract}
The experimental trials were carried out during two successive seasons, 2018 and 2019 at green house of the National Research Centre, Cairo, Egypt. The purpose of this study is to investigate the influence of different chromium concentrations $(0,20,40,60$ and $80 \mathrm{ppm})$ on vegetative growth and chemical constituents of Tilia cordata seedlings. Chromium (Cr) at low concentration (20) significantly increased all growth parameters (plant height, fresh and dry weight of leaves, stems and roots) as well as chlorophyll a, b, carotenoids, carbohydrates and nutrient elements in leaves, stems and roots. But chromium at high concentrations $(40,60$ and $80 \mathrm{ppm})$ significantly decreased all growth characters. Additionally, the same results were obtained on carbohydrates, nitrogen, potassium percentage in leaves, stems and roots and pigment content in leaves. On the contrary, chromium contents in all plant organs increased by increasing $(\mathrm{Cr})$ concentrations. It could be recommended to use chromium concentration at $20 \mathrm{ppm}$ to induce the growth parameters and some chemical compositions of Tilia cordata.
\end{abstract}

Keywords: Tilia seedlings, Vegetative Growth, Chemical constituents, Chromium.

\section{Introduction}

Tilia cordata originates in North America and belongs to the family Tiliacae Family. Its commonly known name is little leaf linden and it can grow up to 80 feet tall and spread to 50 feet wide. Compared to other linden trees, this tree grows at a slower rate, but it is of a great dense of oval to pyramidial crown that cast deep shade. As a prolific bloomer, Tilia cordata gives small flowers of fragrant smell that show in late June and into July, the flowers; fragrance attracts a lot of bees and the dried flowers remain for a long time on the tree. The tree can grow in the sun or in partial shade, it can grow in moisty alkaline soil, but it is not tolerant to drought. The fast rate growth and deep dense shade of this tree made it is favorite among communities, but it is road-salt intolerant. Linden possesses a clear white wood that is soft and can be used in making inexpensive drawer sides.

In agricultural economic crops, the toxicity of heavy metals on plants poses a challenge to scientists concerned with the quality and yield of crop production (Bishehkolaei et al., 2011). Heavy metals harm the efficiency of farming and endangers animals and plants' health (Mudgal et al., 2010). Chromium (Cr) is detected in all living forms and is mostly known as an essential element for humans and animals (Panda and Choudhury, 2005; Bulk et al., 2007). However, sufficient evidence of its essentiality for the growth of plants is lacking (Zayed and Terry, 2003). Chromium contamination of the environment, nowadays, is a he concern; its valence state affects its toxicity to plants since $\mathrm{Cr}(\mathrm{VI})$ is highly toxic and more mobile than Cr (III) (Gupta, et al., 2009).Consumption is how Cr enters the food chain of plant material. It was found that a high dosage of $\mathrm{Cr}$ can be harmful to vegetation (Faisal and Hasanin, 2005; Gbaruko and Friday, 2007).Biological parameters of plants are found to be adversely affected by the increase in $\mathrm{Cr}$ concentration and it can lead to vegetation loss and even barren lands (Dube et al., 2003). Cr is just one of many harmful heavy metals that can cause serious environmental contamination in soil, ground water and sediments. At rates of 0.5 to $5.0 \mathrm{mgL}^{-1}$ in nutrient solution, $\mathrm{Cr}$ is toxic, but it stimulates growth at lower rates (Kumarrai and Kumar, 2010). Cr phytotoxicity symptoms include seed germination and/or early germination seedling development inhibition, root growth reduction, leaf cholorosis and biomass depression (Sharma et al., 1995). Chromium is reported to have an effect on growth of plants, content of pigments, water balance, and 
initial lipid peroxidation which causes inoxidative damage to the plants (Bonet et al., 1991). Chromium was shown to have a noticeable effect on plants metabolism such as that of Hordeum vulgarae (Ali et al,2004), Citrullus (Dube et al., 2003), Cauliflower (Chattajee and Chatterjee, 2001) and Brassica Juncea (Jan et al. 2010). With these aspects in view, this investigation is carried out aiming to study the effect of various concentrations of chromium on the growth and chemical constituents of Tilia corodata.

\section{Materials and Methods}

The experiment was carried out at the greenhouse of the National Research Centre during two successive seasons of 2018 and 2019 to investigate the response of Tilia cordata seedlings grown under polluted condition with Chromium $(\mathrm{Cr})$ metal. The soil of the experimental site was sand of the following characteristics $75.93 \%$ sand, $4.35 \%$ silt, $19.72 \%$ clay, $\mathrm{PH} 7.71, \mathrm{EC} 0.71 \mathrm{dSm}^{-1}, \mathrm{CaCO}_{2} 2.3 \%$, OM 1.58\%, Ca 2.8\% Mg 0.1\%, Na 2.2\%, K 1.56\%, Cl 2.5\%, $\mathrm{So}_{4} 2.8 \mathrm{meqL}^{-1}$.

\section{Plant materials and procedure:}

One year seedlings of Talia cordata were obtained from nursery of forestry Department Horticulture Research Institute, Agriculture Research Centre, the seedlings were planted on the third week of March during the two seasons, as one seedling/pot $30 \mathrm{Cm}$ in diameter filed with ten $\mathrm{Kg}$ soil, the average height of the seedling was $(20-25 \mathrm{~cm})$. The experiments were set in completely randomized design with 5 replicates the treatments used as follows: five chromium levels $(0,20,40,60$ and 80 ppm). Chromium as potassium chromate $\mathrm{K}_{2} \mathrm{CrO}_{4}$ were used after dissolving in distilled water and added as surface irrigation depending on the field capacity. Irrigation regime began after 30 days from transplanting and repeated twice every week till the end of the season $\left(25^{\text {th }}\right.$ November $)$. The available commercially fertilizer used through this experimental NPK was kristalon (N: P: K) produced phayzon company, Holand. The used rate of fertilizer was 5.0 gm per pot in four doses. The plants were fertilized after 4,8,16 and 20 week. The following data were recorded plant height $(\mathrm{cm})$,fresh and dry weigh of leaves, stems and roots $(\mathrm{g})$.The following chemical analysis was determined, chlorophyll a , $\mathrm{b}$ and carotenoids content were determined according to Saric et al ., (1976). Total carbohydrates percentage was determined according to the method by Herbert et al.,(1971 ).Nitrogen and potassium were determined according to the method described by Cottenie et al .,(1982). Chromium was determined by Atomic Absorption Spectrophotometer Perkin-Elmer Model2380 following the method described by Chapman and Pratt (1961). The physical and chemical properties of the soil were determined according to Black et al. (1982). Obtained results were subjected to statistical analysis of variance according to the method described by Snedecor and Cochran (1982) and the combined analysis of the two seasons was calculated according to the method of Steel and Torrie (1982).

\section{Results and Discussion}

\section{Vegetative growth:}

The growth parameters of Tilia cordata as affected by chromium treatments are demonstrated in Table (1): Generally, all growth parameters significantly increased by treating plants with $(\mathrm{Cr})$ at 20 ppm compared with the control. The increments were $(6.50 \%, 33.88 \%, 15.30 \%$ and $10.12 \%$ for plant height, fresh weight of leaves, stems and roots , respectively. and $(35.80 \%, 16.95 \%$, and $14.78 \%$ )for leaves, stems and root dry weight, respectively, in comparison with the control. The lowest values of plant height, fresh weight of leaves, stems and roots and dry weight of leaves, stems and roots were obtained from the plants treated with the maximum concentration of chromium $(80 \mathrm{ppm})$. Numerically, the previous characters decreased by $(13.15,31.38,55.70,36.58,34.03,58.13$ and $41.08 \%$, respectively,) as a result of treatment with chromium at $80 \mathrm{ppm}$ compared with the control. Unfavorable effects of $\mathrm{Cr}$ on the height of plant and the growth of shoot were shown by Rout et al., (1997). The transport of $\mathrm{Cr}$ to the aerial part of the plant could be directly affecting the shoots ' metabolism which in turn affects the plant height of causes its reduction. Phototoxic symptoms in plant cells can occur because of exposure at micro molar orange of $\mathrm{Cr}$ which can cause prevention of germination of seed, degradation of pigments status, balance of nutrients and antioxidant enzymes (Panda and Khan, 2003). Our results were corroborated with the finding of some researches, Rehana et al., (2012) and Nagarajan and Sankar (2014). 
Table 1: Effect of Chromium on plant height, fresh and dry weights of all plant organs of Tilia cordata L. (Average of 2018 and 2019 seasons).

\begin{tabular}{cccccccc}
\hline Characters & Plant height & \multicolumn{3}{c}{ Fresh weight $(\mathbf{g})$} & \multicolumn{3}{c}{ Dry weight(g) } \\
\cline { 3 - 7 } Chromium (ppm) & $(\mathbf{c m})$ & Leaves & Stems & Roots & Leaves & Stems & Roots \\
\hline $\mathbf{0}$ & 129.3 & 46.05 & 127.30 & 47.22 & 16.34 & 53.47 & 23.42 \\
$\mathbf{2 0}$ & 137.7 & 61.65 & 146.78 & 52.00 & 22.19 & 62.53 & 26.88 \\
$\mathbf{4 0}$ & 125.7 & 42.31 & 97.30 & 40.85 & 14.85 & 40.28 & 19.36 \\
$\mathbf{6 0}$ & 115.0 & 37.38 & 74.33 & 35.35 & 12.93 & 29.88 & 16.47 \\
$\mathbf{8 0}$ & 112.3 & 31.60 & 56.40 & 29.95 & 10.78 & 22.39 & 13.80 \\
LSD at 5\% & 3.01 & 2.22 & 7.21 & 4.06 & 0.22 & 0.95 & 0.26 \\
\hline
\end{tabular}

\section{Chemical constituents}

\section{Total carbohydrates content:}

From the given data in Table (2) it could be concluded that total carbohydrates gradually decreased by increasing $\mathrm{Cr}$ concentration from 40 to $80 \mathrm{ppm}$, except plants treated with $\mathrm{Cr}$ at $20 \mathrm{ppm}$ led to increase the total carbohydrates\% in leaves, stems and roots compared with control plants and others concentration of $\mathrm{Cr}$, the increment were (5.94. 3.24 and 7.48\%,respectively). When $\mathrm{Cr}$ was used at 40,60 , and $80 \mathrm{ppm}$,total carbohydrates percentage was reduced by $(15.30,31.09$ and $42.42 \%$ respectively ) in leaves, $(8.72,32.36$ and $32.70 \%$, respectively, ) in stems and $(12.34,26.20$ and 41.75 $\%$,respectively, ) in roots in comparison with the control plants. These results were confirmed by Rehana et al., (2012) on Brassica junceaL.and Nagarajan and Sankar, (2014) on Qryza sativa L. plants.

Pigments content (mg/g F.W.):

The data obtained in Table (2) reported that in leaves chlorophyll (a), (b) and carotenoids increased by $\mathrm{Cr}$ at $20 \mathrm{ppm}$ as compared to the control plants. The increments were (1.53\%) chlorophyll (a), (9.34\%) chlorophyll (b) and (4.27\%) carotenoids compared with the control plants. On the other hand ,chlorophyll (a),(b) and carotenoids decreased by increasing other $\mathrm{Cr}$ concentrations .Chlorophyll content's decrement could be a result of interaction of enzymes that take part in the chlorophyll biosynthetic pathway which could also be a part of the general decrement in the content of chlorophyll in most plants under chromium stress (Shanker et al ., 2005).

Table 2: Effect of Chromium on Carbohydrates percentage in dry weights of all plant organs pigment content (mg/gm F.W) in leaves of Tilia cordata L. (Average of 2018 and 2019 seasons).

\begin{tabular}{ccccccc}
\hline Characters & \multicolumn{3}{c}{$\begin{array}{c}\text { Carbohydrates } \\
\text { (\%) }\end{array}$} & \multicolumn{3}{c}{$\begin{array}{c}\text { Pigment content } \\
\text { (mg/gm F.W) in leaves }\end{array}$} \\
\cline { 2 - 7 } Chromium (ppm) & Leaves & Stems & Roots & Chl (a) & Chl(b) & Caro. \\
\hline $\mathbf{0}$ & 36.73 & 32.11 & 40.12 & 2.421 & 1.210 & 2.811 \\
$\mathbf{2 0}$ & 38.91 & 33.15 & 43.12 & 2.458 & 1.323 & 2.931 \\
$\mathbf{4 0}$ & 31.11 & 29.31 & 35.17 & 2.359 & 1.210 & 2.791 \\
$\mathbf{6 0}$ & 25.31 & 24.61 & 29.61 & 2.162 & 0.913 & 2.411 \\
$\mathbf{8 0}$ & 21.15 & 21.61 & 23.37 & 2.047 & 0.811 & 2.167 \\
\hline
\end{tabular}

\section{Nutrient contents:}

The results obtained in Table (3) indicated That Chromium at $20 \mathrm{ppm}$ increased all macro elements in all plants organs ( leaves, stems and roots ) of Tilia cordata plants .On the contrary, plants treated with chromium at 40,60 and $80 \mathrm{ppm}$ decreased nitrogen percentage in leaves, stem and roots compared with the control . The reductions were $(5.48,30.14$ and $45.21 \%$,respectively, ) in leaves, $(13.11,31.97$ and $50.82 \%$,respectively, ) in stems and $(11.48,25.00$ and $45.69 \%$,respectively, ) in roots in comparison with the control. The reduction in nitrogen content under chromium concentrations may be due to heavy metals disturbing the process of nitrogen metabolism (Dube et al., 2003).

In addition, It is obvious from the data that potassium percentage was markedly decreased in leaves, stems and roots when the plants were treated with the following concentrations of chromium 40 ppm giving $(25.49,1.18$ and $6.45 \%$, respectively, ) 60 ppm giving $(29.41,8.24$ and $6.45 \%$, respectively, ) and $80 \mathrm{ppm}$ giving $(45.10,41.18$ and $13.98 \%$,respectively, ) compared with control plants. Chromium at $20 \mathrm{ppm}$ treatment gave the highest percentage of potassium $(66.67 \%)$ in leaves, $(2.35 . \%)$ in stems and $(16.13 \%)$ in roots compared with the control plants and other $\mathrm{Cr}$ treatments. 
Regarding the effect of chromium treatments on $\mathrm{Cr}$ contents in leaves, stems and roots, the data (3) reported that the adverse effect was obtained by chromium treatments $(20,40,60$ and $80 \mathrm{ppm})$. Chromium content gradually increased by increasing $\mathrm{Cr}$ concentrations. The increments were $(65.12$, $102.32,146.51$ and $193.02 \%$, respectively) in leaves (97.22, $141.67,194.44$ and $250.00 \%$, respectively) in stems and (18.98, 46.30, 65.28 and 86.57\%, respectively) in roots as compared with the control .

Table 3: Effect of Chromium on Percentage of Nitrogen, Potassium and Chromium of all plant organs of Tilia cordata L. (Average of 2018 and 2019 seasons).

\begin{tabular}{cccccccccc}
\hline Characters & \multicolumn{3}{c}{ Nitrogen \% } & \multicolumn{3}{c}{ Potassium\% } & \multicolumn{3}{c}{ Chromium(ppm) } \\
\cline { 2 - 11 } Chromium(ppm) & Leaves & Stems & Roots & Leaves & Stems & Roots & Leaves & Stems & Roots \\
\hline $\mathbf{0}$ & 7.31 & 6.12 & 5.83 & 1.53 & 0.85 & 0.93 & 0.43 & 0.36 & 2.16 \\
$\mathbf{2 0}$ & 8.11 & 7.16 & 6.91 & 2.55 & 0.87 & 1.08 & 0.71 & 0.71 & 2.57 \\
$\mathbf{4 0}$ & 6.89 & 5.31 & 5.13 & 1.14 & 0.84 & 0.87 & 0.87 & 0.87 & 3.16 \\
$\mathbf{6 0}$ & 5.11 & 4.19 & 4.37 & 1.08 & 0.78 & 0.84 & 1.06 & 1.06 & 3.57 \\
$\mathbf{8 0}$ & 4.02 & 3.00 & 3.13 & 0.84 & 0.50 & 0.80 & 1.26 & 1.26 & 4.03 \\
\hline
\end{tabular}

\section{Conclusion}

It could be recommended that using Tilia cordata as phytoremedation plants is suitable in soil polluted with chromium especially the concentration of $20 \mathrm{ppm}$.

\section{References}

Ali, N.A., M.G.L. Ater, and P.Y. Robidoux, 2004. Phytotoxicity and bioaccumulation of copper and chromium using barley (Hordeum vulgare L.) in spiked artificial and natural forest soil. Ecotoxicology and environmental safety, 57: $363-374$.

Bishehkolaei, R., H. Fahimi, S. Saadatmand, T. Nejadsattari, M. Lahouti, and F.T. Yazdi, 2011. Ultrastructural of chromium in Ocimum basilicum. Turk. J. Bot., 35: $261-268$.

Black, C.A., D.D. Evans, L.E. Ensminger, G.L. White, and F.E. Clarke, 1982. Methods of Soil Analysis. Part 2, Agron. Inc. Madison. Wisc., USA. 1-100.

Bonet, A., C. Poschenrieder, and J. Barcelo, 1991. Chromium III-iron interaction in Fe-deficient and Fe-sufficient been plants. 1. Growth and nutrient content. J. Plant Nutr., 14: $403-414$.

Bulk, E., A. Tatsioni, A. Lichtenstein, J. Lau, and A. Pittes, 2007. Effect of chromium supplementation on glucose metabolism and lipids. Diabetes Care, 30: 2154 - 2163.

Chapman, H.D. and P.F. Pratt, 1961. Methods of Analysis for Soils, Plants and Waters. Univ. California Div. Agric. Sci. Berkely USA, 445.

Chatterjee, J., and C. Chatterjee, 2001. Environ. Pollut., 109: 69 - 74.

Cottenie, A., M. Verloo, L. Kiekens, G. Velghe and R. Camerlynck, 1982. Chemical Analysis of Plant and Soil. Laboratory of Analytical and Agrochemistry, state Univ. Ghent Belgium, pp: 100-129.

Dube, B.K., K. Tewari, J. Chatterjee, and C. Chatterejee, 2003. Excess chromium alters uptake and translocation of certain nutrients in citrullus. Chemosphere, 53: $1147-1153$.

Faisal, U. and S. Hasnain, 2005. Chromate resistant Bacillus cereus augments sunflower growth by reducing toxicity $\mathrm{Cr}$ (VI). J. Plant Biol., 48: 187 - 194.

Gbaruko, B.C. and O.U. Friday, 2007. Bioaccumulation of heavy metals in some found and flora. Int. J. Environ. Sci. Tech., 4: $197-202$.

Gupta, S., S. Srivastava, and P.P. Saradni, 2009. Chromium increases photosystem 2 activities in Brassica juncea. Biol. Plant, 53: 100 - 104.

Herbert, D.P., P. Phlipps, and R. Strangle, 1971.Determination of carbohydrates. Method in Microbial, 58, 209-344.

Jan, S., T. Parween, T.Q. Siddiqui, U. Mahmood and A. Ahmed, 2010. The antioxidative response system Brassica joncea L. cv. Pusa Jaikisan. Exposed to Hexavalent chromium. World J. Agric. Sci., 6 (4): 425 - 433.

Kumarrai, P. and G. Kumar, 2010. The genotoxic potential of two heavy metals in inbred lines of maize (Zea mays L.). Turk. J. Bot., 34: 39 - 46.

Mudgal, V., N. Madaan, and A. Mudgal, 2010. Heavy metals in plants: phytoremediation: Plants used to remediate heavy metal pollution. Agric. Biol. J. North. Am. $215-7517$. 
Nagarajan, M. and G.K. Sankar, 2014. Effect of chromium on growth, biochemicals and nutrient accumulation of paddy (Qryza sativa L.). International Letters of Natural Sciences, (23): $8-19$.

Panda, S.K. and S. Choudhury, 2005. Chromium stress in plants. Braz. J. Plant Physiol., 17: 95 - 102.

Panda, S.K. and M.H. Khan, 2003. Antioxidant efficiency in rice (Oryza sativa) leaves under heavy metal toxicity. J. Plant Biol., 30: $631-633$.

Rehana, H., A.J. Parray, N.A. Kamili, and U. Mahmood, 2012. Chromium stress in Brassica juncea L. cv. Pusa Jai Kissan under hydroponic culture. African Journal of Biotechnology,11 (90): 15658 $-15663$.

Rout, G.R., S. Samantaray, and P. Das, 1997. Differential chromium tolerance among eight mung been cultivars grown in nutrient culture. J. Plant Nutr., 20: $473-483$.

Saric , M., R. Kostrori , T. Guppina and L. Geris, 1976 . Chlorophyll determination Univ. SaduPrakitikum is KiziologizeBilijaka-Beagrad, Haucua Anjiga, 215.

Shanker, A.K., C. Cervantes, H.L. Tavera, and S. Avudainanyagam, 2005. Environ. Int., 30: 739 -753

Sharma, D.C., C. Chatterjee and C.P. Sharma, 1995. Chromium accumulation by barley seedlings (Hordeum vulgare L.). Journal of experimental botany, 25: $241-251$.

Snedcor, G.W. and W.G. Cochran, 1980. One-way Classification Analysis of Variance. In: Statistical Methods (8 edition ).Iowa State University Press Ames. Iowa, U.S.A., Chapter, 12: 217-236.

Steel, R.G.D. and J.H. Torrie, 1982. Principles and Procedures of statistics. Mc grow-hill book Co., Inc., New York. Toronto, London.

Zayed, A.M., and N. Terry, 2003. Plant and Soil, 249: 139- 156. 